\title{
Factors Affecting Turnover Intension of Long Term Care Hospitals Nurses
}

\author{
요양병원 간호사의 이직 의도에 미치는 영향 \\ Seung Hee Han ${ }^{1}$ \\ 한승희 ${ }^{1}$ \\ ${ }^{1}$ Assistamt Professor, Dept. Nursing, Gwangju University, Korea, shhanj@gwangju.ac.kr
}

\begin{abstract}
The purpose of this study is to investigate on the effect of communication ability, job satisfaction, job stress on turnover of nursing hospital nurses. A total of 214 long term care hospitals nurses participated in the study from January 5 to 30, 2020. For data analysis, the IBM SPSS Win 22.0 version Program was used. Characteristics of the subjects and variables were analyzed using frequency and mean and standard deviation. Differences between variables according to subject characteristics were determined by t-test, ANOVA, and Pearson;s correlation coefficients. The effect on turnover intention was analyzed through regression analysis. The results show that the turnover intention and job satisfaction of the subjects has a negative correlation, and turnover intention and communication ability has a negative correlation. However, there was no correlation between job stress and turnover intention. In addition, the factors affecting the turnover intention of the subjects were found to be communication skills, and job stress and job satisfaction were not the influencing factors, and the explanatory power of the model was $26 \%$. Through this study, it is suggested that a program to improve communication ability should be developed to lower the turnover intention of long term care hospitals nurses, and various studies should be conducted by adding variables that can affect nursing hospital nurses.
\end{abstract}

Keywords: Long Term Care Hospitals Nurses, Communication Ability, Job Satisfaction, Job Stress, Turnover Intension

요약: 본 연구의 목적은 요양병원 간호사의 의사소통 능력, 직무만족도, 직무스트레스가 이직 의도에 미치는 영향을 파악하기 위한 서술적 조사연구이다. 요양병원 간호사 214 명을 대상으로 2020년 1월5일부터 30일까지 이루어졌다. 자료 분석 방법은 IBM SPSS Win 22.0 version Program을 이용하였다. 대상자의 특성과 변수는 빈도 분석과 평균 및 표준편차를 구했고, 대상자 특성에 따른 변수들 간의 차이는 t-test, ANOVA, Pearson;s correlation coefficients로 하였으며, 이직 의도에 미치는 영향에 대해서는 회귀분석으로 분석하였다. 연구대상자의 이직의도와 직무만족도는 부적 상관관계를 보였고, 이직의도와 의사소통 능력도 부적 상관관계를 보였다. 하지만 직무스트레스와 이직의도는 상관관계가 없었다. 또한 대상자의 이직의도에 영향을 미치는 요인은 의사소통 능력으로 나타났으며 직무스트레스와 직무만족도는 영향을 미치는 요인이 아니었으며, 모형의 설명력은 $26 \%$ 로 나타났다. 본 연구를 통해 요양병원 간호사의 이직의도를 낮추기 위해 의사소통 능력을 향상할수 있는 프로그램 개발이 이루어져야 하며, 요양병원 간호사들에게 영향을 줄 수 있는 변수를 추가하여 다양한 연구가 필요할 것을 제언한다.

Received: June 18, 2021; $1^{\text {st }}$ Review Result: August 02, 2021; ${ }^{\text {nd }}$ Review Result: September 16, 2021 Accepted: October 31, 2021 
핵심어: 요양병원 간호사, 의사소통능력, 직무만족도, 직무스트레스, 이직의도

\section{1. 서론}

우리나라는 첨단화된 의료 기술의 발달과 국민 생활 수준의 향상으로 평균 수명이 연장되고 노령화가 빠르게 진행되고 있으며 고령화 사회에서 고령 사회로 접어들고 있다[1]. 현재 빠른 속도의 인구 고령화로 평균 수명이 연장되는 노인 인구의 증가로 인해 65 세 이상의 노년 인구는 $14.3 \%$ 로 조사되었고, 2025 년에는 $20.0 \%$ 의 노년 인구를 예상하며, 후기 고령 사회가 될 것으로 통계청[2]은 예측하였다. 또한 노화로 인한 신체적 기능 저하와 만성 질환의 증가로 요양 병원으로 입원하는 노인이 증가하고 있는 추세를 보이고 있다[3]. 이러한 노년 인구의 증가는 치매, 중풍 등 장기요양 보호 노인들이 증가하여 이들을 위한 전문 요양병원 및 요양 시설이 2008년에 690개에서 2018년 1,544개로 급속이 증가하고 있다[4].

요양병원에 입원하는 노인환자의 대부분은 자신의 일상생활이 어려운 노인성 질환, 만성질환을 않은 자로 많은 부분을 간호사에게 의존하게 되고 의학적인 처지와 간호, 재활을 포함한 통합적인 의료 서비스를 받고 있다[5][6]. 간호사는 대부분 3교대 근무의 특수성, 근무 조건, 간호 요구의 증가 등으로 다른 분야에 비해 스트레스가 많다[5]. 특히 요양병원의 경우 간호 인력의 인건비의 이유로 간호사보다는 간호조무사 채용을 더 많이 하는 경우가 많다[6]. 이로 인해 간호사 인력부족은 과중한 업무와 직무에 대한 만족감이 감소하고 직무스트레스로 인해 부정적인 영향으로 간호의 질이 감소하고 있다[5]. 이로 인해 간호사들의 이직이 유도되고 있으며, 재직 중인 간호사들에게도 업무가 가중되어 직무만족도 저하로 간호의 질이 떨어질 수 있다[5].직무만족도는 자신이 근무하는 병원에 지속해서 근무하게 하는 요인이며, 이직 의도에도 영향을 미친다.

요양병원의 조직에서 의료서비스의 질을 향상하기 위해서는 숙련되고 전문화된 간호사를 유지하는 것이 필요하며[7], 조직의 유효성을 향상하기 위해서는 효율적인 의사소통이 의료기관 내 인력 간의 이해를 소통시키고, 간호의 업무를 향상하는데 도움이 되는 것으로 나타났다[8]. 특히 요양병원 간호사는 장기입원하는 노인환자의 돌봄, 간호조무사 및 간병인 교육 및 관리 감독, 중환자와 임종 대상자의 신체적, 심리적 간호를 제공하는 다양한 업무로 인해 급성기 병원 간호사와는 다른 업무의 특성이 있다[9][10]. 따라서, 요양병원 간호사의 의사소통 능력은 환자 치료뿐만 아니라 병원 및 간호업무의 성과에 도움이 되는 것으로 나타났고[9], 의사소통 능력이 낮을수록 직무스트레스 및 이직의도와도 관련이 있다고 보고하고 있어 의사소통 능력이 매우 중요한 변수임을 알 수 있다[11].

이러한 요양병원 간호사는 장기 요양 대상자와 노인 만성질환자에 대한 간호사의 의존도 및 요구도가 높은 업무와 노인 대상자의 낙상에 의한 위험도와 안전사고의 발생이 높고, 과중한 업무량으로 인한 직무스트레스가 높게 나타났다[12]. 이러한 직무 스트레스는 신체적 및 정신적 건강에 해롭고, 직무만족에도 심각한 문제를 초래할 수 있다[13]. 요양병원 간호사의 직무스트레스는 이직률이 높아지고, 간호사 수가 부족하고, 남아있는 동료 간호사의 업무가 가중되는 악순환이 반복되고 있는 것이 현실이다[14]. 
요양병원 간호사를 대상으로 의사소통 능력, 직무만족도, 직무스트레스, 이직 의도와의 관계를 살펴본 연구는 많지 않아서 이와 관련된 요인을 확인하여 요양병원 간호사의 이직의도를 낮출 수 있는 기초자료를 제공하고자 한다.

\section{2. 연구 방법}

\section{1 연구설계}

본 연구는 요양병원 간호사의 의사소통 능력, 직무만족도, 직무스트레스가 이직의도에미치는 영향을 파악하기 위한 서술적 조사연구이다.

\section{2 연구대상자}

본 연구는 현재 건강보험 심사평가원(http://www.hira.or.kr)에 등록된 요양병원과 S 시와 $\mathrm{Y}$ 시에 위치한 요양병원 중 100 병상 이상의 요양병원 중 자료 수집을 허락한 18 개 병원에 서 근무하는 요양병원 간호사를 대상으로 하였다. 표본 수는 G-power 3.1.9.2 program을 이용하여 효과 크기(effect size). 15 (중간), 유의수준( $\alpha$ ).05, 검정력(1- $\beta$ ) 95\%, 예측 변수 16 개를 고려하여 회귀분석에 필요한 표분수는 204 명이었다. 배포된 설문지 250 부 중 230 부를 회수하였으며 회수된 설문지 중 응답이 불성실한 설문지 6 부를 제외한 214 부 를 분석에 활용하였다.

\section{3 연구 도구}

\subsection{1 의사소통 능력}

본 연구에서는 Hur[15]가 가 개발한 GICC(Global Interpersonal Communication Competency Scale)을 이현숙 외[16]가 수정 보완한 도구를 이용하여 측정하였다. 본 도 구는 총 15 문항으로 구성되어 있고 각 문항은 '전혀 그렇지 않다' 1점에서 '매우 그 렇다' 5점 Likert 척도로 측정되며 점수가 높을수록 의사소통 능력이 높음을 의미한다. 개발 당시 도구의 신뢰도는 Cronbach's $\alpha$ 는 .72이었으며 본 연구에서의 신뢰도는 Cronbach's $\alpha$ 는 .88이었다.

\subsection{2 직무만족도}

본 연구에서는 Slavitt 등[17]이 개발한 도구를 Jo[10]가 수정하고 보완한 설문지를 이용하였다. 본 도구는 총 33 문항으로 구성되어 있고 각 문항은 '전혀 그렇지 않다 1점 에서 '매우 그렇다' 5점 Likert 척도로 측정되며 점수가 높을수록 직무 만족이 높음을 의미한다. 개발 당시 도구의 신뢰도는 Cronbach' $\mathrm{s} \alpha$ 는 .91이었으며 본 연구에서의 신뢰 도는 Cronbach's $\alpha$ 는 .88이었다.

\subsection{3 직무 스트레스}

본 연구에서는 Kim \& Gu[18]가 개발한 도구를 Park 등[14]이 수정하고 보완한 설문지 를 이용하였다. 본 도구는 총 25 문항으로 구성되어 있고 각 문항은 '전혀 못 느낀다' 1점에서 ‘아주 심하게 느낀다' 5점 Likert 척도로 측정되며 점수가 높을수록 직무 스 트레스가 높음을 의미한다. 개발 당시 도구의 신뢰도는 Cronbach' $\mathrm{s} \alpha$ 는 .94이었으며 본 
연구에서의 신뢰도는 Cronbach's $\alpha$ 는 .91이었다.

\subsection{4 이직 의도}

본 연구에서는 Mobley[19]가 개발한 도구를 $\operatorname{Kim}[20]$ 이 수정하고 보완한 설문지를 이용 하였다. 본 도구는 총 6 문항으로 구성되어 있고 각 문항은 '전혀 그렇지 않다' 1점에 서 '매우 그렇다' 5점 Likert 척도로 측정되며 점수가 높을수록 이직 의도가 높음을 의미한다. Kim[20]의 연구에서 Cronbach' $\mathrm{s} \alpha=.76$ 이었고 본 연구에서 Cronbach' $\mathrm{s} \alpha=.88$ 이었다.

\section{4 자료수집 방법 및 윤리적인 고려}

자료수집 기간은 2020 년 1 월 5 일부터 1 월 30 일까지 연구에 동의한 요양병원의 간호부를 본 연구자가 직접 방문하여 연구의 목적과 취지 및 설문지 작성법을 설명한 후 협조를 구하였다. 대상자에게 자료 수집을 하기 전에 연구자가 연구의 목적, 내용, 절차, 참여시 익명성 및 비밀 보장, 자료 활용 범위, 자발적인 참여 동의 및 거부, 참여 중 중도 포기 가능 등의 내용을 충분하게 설명하였고, 연구 후 폐기 등의 내용을 충분하게 설명하였다. 대상자에게 자유롭게 질문을 하도록 한 뒤 자발적으로 참여하기로 동의한 간호사에게 연구 참여 동의서를 받은 후 설문지를 배부하였다. 설문지는 18 개 요양병원에 총 250 부의 설문지를 배부하여 214 부를 분석에 활용하였다. 설문에 참여한 대상자에게는 소정의 답례품을 제공하였다.

\section{5 자료 분석 방법}

수집된 자료는 IBM SPSS Win 22.0 version Program 을 이용하여 전산처리하였다.

가. 대상자의 일반적 특성은 기술통계를 사용하여 구하였다.

나. 대상자의 의사소통 능력, 직무만족도, 직무 스트레스, 이직 의도의 정도를 알아보기 위하여 평균과 표준편차 범위를 구하였다.

다. 대상자의 일반적 특성에 따른 의사소통 능력, 직무만족도, 직무 스트레스, 이직 의도의 정도를 파악하기 위해 t-test 와 ANOVA 를 수행하였고, 사후 검증은 Scheffe' s test 로 확인하였다.

라. 대상자의 의사소통 능력, 직무만족도, 직무 스트레스, 이직 의도간의 상관관계는

Pearson's Correlation coefficient 로 분석하였다.

마. 대상자의 이직 의도에 영향을 미치는 요인을 파악하기 위해 Multiple regression 으로 분석하였다.

\section{3. 연구 결과}

\section{1 연구대상자의 일반적 특성}

대상자의 일반적 특성은 먼저 남성은 12 명 (5.6\%)이고 여성은 202명 (94.4\%)으로 나타났 다. 연령은 20세 30세가 144명(67.3\%)이고 31세 40세가 61명(28.5\%)이었다. 학력은 전문 학사 졸업이 46 명(21.5\%)이고 학사학위가 124명(57.9\%)이었다. 경력은 1년 10년이 164명 
(76.6\%)가 가장 많았고, 11 년에서 20년이 41명(19.2\%)이었다. 직위는 일반 간호사가 198 명 (92.5\%)가 대부분이었고, 근무 형태는 3 교대 근무가 163 명 $(76.2 \%)$, 상근근무가 49명 (22.9\%)이었다. 급여는 200만원-299만원이 170명(79.4\%), 300만원-399만원이 40명(18.7\%) 이었으며, 건강 상태에서 건강하다가 104명(48.6\%), 보통이다가 100명(46.7\%)이었다.

[표 1] 연구 대상자의 일반적 특성

[Table 1] General Characteristics of Subjects $(\mathrm{N}=214)$

\begin{tabular}{|c|c|c|c|}
\hline Characteristic & Categories & $\mathrm{N}$ & $\%$ \\
\hline \multirow{2}{*}{ 성별 } & 남 & 12 & 5.6 \\
\hline & 여 & 202 & 94.4 \\
\hline \multirow{3}{*}{ 나이 } & $20 \sim 30$ & 144 & 67.3 \\
\hline & $31 \sim 40$ & 61 & 28.5 \\
\hline & 41세 이상 & 9 & 4.2 \\
\hline \multirow{4}{*}{ 학력 } & 전문학사 & 46 & 21.5 \\
\hline & 학사과정 & 42 & 19.6 \\
\hline & 학사학위 & 124 & 57.9 \\
\hline & 대학원 & 2 & 0.9 \\
\hline \multirow{3}{*}{ 경력 } & 1 10년 & 164 & 76.6 \\
\hline & 11년 20년 & 41 & 19.2 \\
\hline & 21년 30년 이상 & 2 & 0.9 \\
\hline \multirow{3}{*}{ 직위 } & 일반간호사 & 198 & 92.5 \\
\hline & 책임간호사 & 2 & 0.9 \\
\hline & 수간호사 & 14 & 6.5 \\
\hline \multirow{3}{*}{ 근무 형태 } & 3교대 근무 & 163 & 76.2 \\
\hline & 상근근무 & 49 & 22.9 \\
\hline & 기타 & 2 & 0.9 \\
\hline \multirow{3}{*}{ 급여 } & 200 299만원 & 170 & 79.4 \\
\hline & 300 399만원 & 40 & 18.7 \\
\hline & 400 이상 & 4 & 1.9 \\
\hline \multirow{3}{*}{ 건강 상태 } & 건강하다 & 104 & 48.6 \\
\hline & 보통이다 & 100 & 46.7 \\
\hline & 건강하지 않다 & 10 & 4.7 \\
\hline
\end{tabular}

\section{2 연구대상자의 의사소통 능력, 직무만족도, 직무 스트레스, 이직 의도 정도}

대상자의 의사소통 능력은 평균 $3.36 \pm 0.64$ 점, 직무만족도는 $2.94 \pm 0.36$ 점, 직무 스트레스는 $2.16 \pm 0.60$ 점, 이직 의도는 $3.36 \pm 0.64$ 점으로 나타났다.

[표 2] 연구대상자의 의사소통 능력, 직무만족도, 직무 스트레스, 이직 의도의 정도

[Table 2] Descriptive Statistics of Communication Ability, Job Satisfaction, Job Stress, Turnover Intension $(\mathrm{N}=214)$

\begin{tabular}{c|c|c|c}
\hline Variables & $\mathrm{M} \pm \mathrm{SD}$ & Minimum & Maximum \\
\hline 의사소통 능력 & $3.36 \pm 0.64$ & 1.00 & 4.00 \\
\hline 직무만족도 & $2.94 \pm 0.36$ & 1.63 & 4.32 \\
\hline
\end{tabular}




\begin{tabular}{c|c|c|c}
\hline 직무 스트레스 & $2.16 \pm 0.60$ & 2.89 & 4.13 \\
\hline 이직 의도 & $3.36 \pm 0.64$ & 1.00 & 4.73 \\
\hline
\end{tabular}

3.3 연구대상자의 일반적 특성에 따른 의사소통 능력, 직무만족도, 직무 스트레스, 이직 의도의 차이

대상자의 일반적 특성에 따른 의사소통 능력은 건강상태 $(\mathrm{F}=3.338, \mathrm{p}<.05)$ 에 따른 통계 적으로 유의한 차이를 보였으며, 성별, 연령, 학력, 경력, 직위, 근무 형태, 급여에 있 어 그 차이가 통계적으로 유의하지 않았다. 일반적 특성 중 차이가 있는 부분의 사후분 석 결과 건강상태는 '건강하지 않다' 보다 '건강하다' 라고 응답한 사람이 의사소통 능력이 높았다.

대상자의 일반적 특성에 따른 직무만족도는 학력 $(\mathrm{F}=2.320, \mathrm{p}<.01)$ 에 따라 통계적으로 유의한 차이를 보였으며, 성별, 연령, 경력, 직위, 근무 형태, 급여, 건강 상태에 있어 그 차이가 유의하지 않았다. 일반적 특성 중 차이가 있는 부분의 사후분석 결과는 그룹 간 유의한 차이가 없었다.

대상자의 일반적 특성에 따른 직무 스트레스는 경력 $(\mathrm{F}=3.949, \mathrm{p}<.001)$, 급여 $(\mathrm{F}=3.555$, $\mathrm{p}<.001$ )에 따라 통계적으로 유의한 차이를 보였으며, 성별, 연령, 학력, 직위, 근무 형 태, 건강 상태에 있어 그 차이가 통계적으로 유의하지 않았다. 일반적 특성 중 차이가 있는 부분의 사후분석 결과 직무 스트레스는 경력이 '21년 30년' 보다 ' 1 년 10년' 이 라고 응답한 사람이 직무 스트레스가 높았고, 급여가 ‘ 400 만원 이상' 인 사람보다는 '200만원 299만원' 이라고 응답한 사람이 직무 스트레스가 높았다.

대상자의 일반적 특성에 따른 이직의도는 학력 $(\mathrm{F}=4.012, \mathrm{p}<.001)$, 근무 형태 $(\mathrm{F}=3.816$, $\mathrm{p}<.001)$, 건강 상태 $(\mathrm{F}=4.183, \mathrm{p}<.001)$ 에 따라 통계적으로 유의한 차이를 보였으며, 성별, 연령, 경력, 직위, 급여에 있어 그 차이가 통계적으로 유의하지 않았다. 일반적 특성 중 차이가 있는 부분의 사후분석 결과 이직의도는 학력에서 '학사학위 졸업' 보다 '학사 과정 졸업' 이라고 응답한 사람, 근무형태가 '상근 근무' 보다는 '3교대 근무' 라고 응답한 사람, 건강 상태에서 '보통이다' 보다 '건강하지 않다' 라고 응답한 사람이 이 직 의도가 높았다.

[표 3] 일반적 특성에 따른 의사소통 능력, 직무만족도, 직무 스트레스, 이직 의도 정도의 차이

[Table 3] Descriptive Statistics of Communication Ability, Job Satisfaction, Job Stress, Turnover Intension according to General Characteristics $(\mathrm{N}=214)$

\begin{tabular}{|c|c|c|c|c|c|c|c|c|c|}
\hline \multirow{2}{*}{ Characteristics } & \multirow{2}{*}{ Categories } & \multicolumn{2}{|c|}{ 의사소통능력 } & \multicolumn{2}{|c|}{ 직무만족도 } & \multicolumn{2}{|c|}{ 직무스트레스 } & \multicolumn{2}{|c|}{ 이직의도 } \\
\hline & & $\mathrm{M} \pm \mathrm{SD}$ & $\mathrm{t} / \mathrm{F}$ & $\mathrm{M} \pm \mathrm{SD}$ & $\mathrm{t} / \mathrm{F}$ & $\mathrm{M} \pm \mathrm{SD}$ & $\mathrm{t} / \mathrm{F}$ & $\mathrm{M} \pm \mathrm{SD}$ & $\mathrm{t} / \mathrm{F}$ \\
\hline \multirow{2}{*}{ 성별 } & 남 & $3.19 \pm 0.34$ & \multirow{2}{*}{.360} & $2.94 \pm 0.33$ & \multirow{2}{*}{-.201} & $2.16 \pm 0.60$ & \multirow{2}{*}{.461} & $3.37 \pm 0.64$ & \multirow{2}{*}{.604} \\
\hline & 여 & $3.15 \pm 0.44$ & & $2.96 \pm 0.68$ & & $2.08 \pm 0.60$ & & $3.25 \pm 0.75$ & \\
\hline \multirow{3}{*}{ 연령 } & 20-30세a & $3.19 \pm 0.36$ & \multirow{3}{*}{0.047} & $2.91 \pm 0.38$ & \multirow{3}{*}{1.179} & $2.17 \pm 0.56$ & \multirow{3}{*}{1.130} & $3.34 \pm 0.71$ & \multirow{3}{*}{.885} \\
\hline & 31-40세b & $3.18 \pm 0.33$ & & $3.00 \pm 0.28$ & & $2.18 \pm 0.67$ & & $3.44 \pm 0.47$ & \\
\hline & 41세 이상c & $3.21 \pm 0.22$ & & $2.99 \pm 0.32$ & & $1.86 \pm 0.68$ & & $3.17 \pm 0.52$ & \\
\hline 학력 & 전문학사졸업a & $3.18 \pm 0.35$ & 1.186 & $3.03 \pm 0.23$ & $2.320^{*}$ & $2.28 \pm 0.60$ & 1.002 & $3.40 \pm 0.44$ & 4.012 \\
\hline
\end{tabular}




\begin{tabular}{|c|c|c|c|c|c|c|c|c|c|}
\hline & 학사과정졸업b & $3.10 \pm 0.27$ & & $2.84 \pm 0.32$ & & $2.17 \pm 0.60$ & & $3.64 \pm 0.58$ & $* * *$ \\
\hline & 학사학위졸업c & $3.22 \pm 0.37$ & & $2.94 \pm 0.40$ & & $2.10 \pm 0.58$ & & $3.26 \pm 0.71$ & \\
\hline & 대학원졸업d & $3.20 \pm 0.00$ & & $3.15 \pm 0.00$ & & $2.38 \pm 1.38$ & & $3.18 \pm 0.00$ & \\
\hline \multirow{3}{*}{ 경력 } & 1 10년a & $3.19 \pm 0.35$ & \multirow{3}{*}{.092} & $2.94 \pm 0.37$ & \multirow{3}{*}{.127} & $2.18 \pm 0.56$ & \multirow{3}{*}{$\begin{array}{c}3.949 \\
* * * \\
a>c\end{array}$} & $3.32 \pm 0.65$ & \multirow{3}{*}{1.431} \\
\hline & 11- 0년b & $3.17 \pm 0.29$ & & $2.92 \pm 0.32$ & & $2.05 \pm 0.67$ & & $3.51 \pm 0.63$ & \\
\hline & 21 30년c & $3.13 \pm 0.00$ & & $3.05 \pm 0.00$ & & $1.12 \pm 0.11$ & & $3.36 \pm 0.00$ & \\
\hline \multirow{3}{*}{ 직위 } & 일반간호사a & $3.18 \pm 0.35$ & \multirow{3}{*}{.166} & $2.93 \pm 0.38$ & \multirow{3}{*}{1.400} & $2.16 \pm 0.59$ & \multirow{3}{*}{.765} & $3.37 \pm 0.65$ & \multirow{3}{*}{.201} \\
\hline & 책임간호사b & $3.33 \pm 0.00$ & & $3.26 \pm 0.00$ & & $2.46 \pm 0.36$ & & $3.09 \pm 0.00$ & \\
\hline & 수간호사c & $3.19 \pm 0.20$ & & $3.04 \pm 0.29$ & & $2.00 \pm 0.69$ & & $3.33 \pm 0.60$ & \\
\hline \multirow{3}{*}{ 근무 형태 } & 3교대a & $3.20 \pm 0.34$ & \multirow{3}{*}{.783} & $2.93 \pm 0.34$ & \multirow{3}{*}{.697} & $2.13 \pm 0.60$ & \multirow{3}{*}{.796} & $3.43 \pm 0.64$ & \multirow{3}{*}{$\begin{array}{c}3.816 \\
* * * \\
a>b\end{array}$} \\
\hline & 상근근무b & $3.13 \pm 0.37$ & & $2.98 \pm 0.43$ & & $2.24 \pm 0.57$ & & $3.15 \pm 0.62$ & \\
\hline & 기타c & $3.20 \pm 0.00$ & & $3.15 \pm 0.00$ & & $2.38 \pm 1.38$ & & $3.18 \pm 0.00$ & \\
\hline \multirow{3}{*}{ 급여 } & 200 -299만원a & $3.19 \pm 0.35$ & \multirow{3}{*}{.886} & $2.93 \pm 0.36$ & \multirow{3}{*}{1.466} & $2.17 \pm 0.58$ & \multirow{3}{*}{$\begin{array}{c}3.555 \\
* * * \\
a>c\end{array}$} & $3.34 \pm 0.65$ & \multirow{3}{*}{1.550} \\
\hline & 300 -399만원b & $3.16 \pm 0.31$ & & $2.94 \pm 0.33$ & & $2.19 \pm 0.65$ & & $3.48 \pm 0.60$ & \\
\hline & 400 이상c & $3.44 \pm 0.26$ & & $3.29 \pm 0.21$ & & $1.25 \pm 0.27$ & & $2.87 \pm 0.41$ & \\
\hline \multirow{3}{*}{ 건강 상태 } & 건강하다a & $3.23 \pm 0.36$ & \multirow{3}{*}{$\begin{array}{c}3.338 \\
* \\
a>c\end{array}$} & $2.98 \pm 0.30$ & \multirow{3}{*}{1.389} & $2.17 \pm 0.54$ & \multirow{3}{*}{1.389} & $3.23 \pm 0.77$ & \multirow{3}{*}{$\begin{array}{c}4.183 \\
* * * \\
c>b\end{array}$} \\
\hline & 보통이다b & $3.17 \pm 0.32$ & & $2.91 \pm 0.41$ & & $2.15 \pm 0.66$ & & $3.49 \pm 0.48$ & \\
\hline & 건강하지않다c & $2.94 \pm 0.32$ & & $2.84 \pm 0.19$ & & $1.99 \pm 0.49$ & & $3.41 \pm 0.23$ & \\
\hline
\end{tabular}

* 참조 : $* \mathrm{p}<.05, * * \mathrm{p}<.01, * * * \mathrm{p}<.001$

\section{4 연구대상자의 의사소통 능력, 직무만족도, 직무 스트레스, 이직 의도와의 상관관계}

대상자의 의사소통 능력, 직무만족도, 직무 스트레스, 이직 의도와의 상관관계를 분석 한 결과, 의사소통 능력과와 직무만족도 $(\mathrm{r}=.446, \mathrm{p}<.001)$ 는 유의한 양의 상관관계가 있 고, 의사소통 능력과 이직 의도 $(\mathrm{r}=-.179, \mathrm{p}<.01)$, 직무만족도와 의직 의도 $(\mathrm{r}=-.512$, $\mathrm{p}<.001)$ 와는 유의한 음의 상관관계가 있었다. 즉, 의사소통 능력이 높을수록 직무만족도 가 높고, 의사소통 능력과 직무만족도가 낮을수록 이직 의도가 높다는 것을 알 수 있다.

[표 4] 연구대상자의 의사소통 능력, 직무만족도, 직무 스트레스, 이직 의도와의 상관관계

[Table 4] Correlation between Communication Ability, Job Satisfaction, Job Stress, Turnover(N=214)

\begin{tabular}{c|c|c|c|c}
\hline Variables & 의사소통능력 & 직무만족도 & 직무스트레스 & 이직의도 \\
\hline 의사소통 능력 & 1 & & & \\
\hline 직무만족도 & $446^{* * *}$ & 1 & & \\
\hline 직무 스트레스 & .041 & .051 & 1 & \\
\hline 이직 의도 & $-.179 * *$ & $-.512^{* * *}$ & .003 & 1 \\
\hline
\end{tabular}

* 참조 : *p<.05, **p<.01, ***p<.001

\section{5 연구대상자의 이직 의도에 영향을 미치는 요인}


이직 의도에 영향을 미치는 요인을 확인하기 위해서 의사소통 능력, 직무만족도, 직무 스트레를 독립변수로 하여 회귀분석을 실시한 결과 전체 모형 설명력(R2)은 .263으로 통 계적으로 유의하였다 $(\mathrm{F}=75.516, \mathrm{p}<.001)$. 의직 의도에 영향을 미치는 요인은 직무만족도 $(\beta=-.541 \mathrm{p}<.001)$ 로 나타났다.

[표 5] 이직 의도에 영향을 미치는 요인

[Table 5] Influencing Factors on Tunover Intension ( $=214)$

\begin{tabular}{c|c|c|c|c|c}
\hline Variables & $\mathrm{B}$ & Std. Error & Beta & $\mathrm{t}$ & Sig. \\
\hline Constant & 5.799 & .410 & & 14.154 & .000 \\
\hline 의사소통 능력 & .114 & .122 & .062 & .931 & .353 \\
\hline 직무만족도 & -.971 & .119 & -.541 & -8.192 & .000 \\
\hline 직무 스트레스 & .030 & .084 & .028 & .468 & .640
\end{tabular}

$R^{2}=263 \mathrm{~F}=75.516 \mathrm{p}<.001$

\section{4. 논의}

본 연구는 요양병원 간호사를 대상으로 의사소통 능력, 직무만족도, 직무 스트레스 및 이직 의도 정도를 파악하고 이직 의도에 영향을 미치는 요인을 파악하여 요양병원 간호 사의 이직을 최소화하여 효율적인 요양병원 간호인력 관리를 위한 기초 자료를 제공하고 자 시도하였다.

대상자의 의사소통 능력은 5점 만점에 평균 3.36점으로 나타났다. 요양병원 간호사를 대상으로 한 Jung[21]은 3.56점, Han \& Park[22]은 3.56점 으로 나타나 본 연구 결과와 유사하였고 평균 이상으로 높게 나왔다. 의사소통 능력은 직종 간에 효율적인 업무와 문 제해결을 위해 중요하며, 특히 요양병원 간호사는 대상자가 고령 환자와 만성질 환자가 많은 업무의 특성상 의사소통 능력이 매우 중요할 것으로 생각된다. 본 연구에서 일반적 특성에 따른 의사소통 능력의 사후분석 결과 건강상태에서 건강하다고 말한 사람이 의사 소통 능력이 높게 나왔으나 Han \& Park[23]의 연구에서는 연령, 결혼 상태, 월 소득에 유의한 차이를 보여 본 연구 결과와 차이가 있었다.

대상자의 직무만족도는 5점 만점에 평균 2.94점으로 나타났다. 요양병원 간호사를 대 상으로 한 Jung[21]의 연구에서 평균 2.88점으로 나와 본 연구 결과와 유사하였다. 직무 만족도는 학력에 따라 유의한 차이를 보였으나 다른 변수에서 그룹 간 차이를 보이지는 않았고 Lee, Lee \& Choy[22]의 연구에서도 모든 변수에서 그룹간 차이를 보이지 않았고, 연령, 직위, 등이 직무 만족에 영향을 주는 결과로 나와 본 연구 결과와 일부 일치하였 다. 다른 선행 연구에서 종합병원 간호사의 직무만족도는 3.30점[24], 일반병동 간호사 는 3.94점[25]으로 요양병원 간호사의 직무만족도가 상대적으로 낮은 수준이여서 급성기 병원과 요양병원 간호사의 직무만족도에 대한 비교 연구가 필요할 것으로 생각된다.

대상자의 직무 스트레스는 5점 만점에 평균 2.16점으로 나타났다. 요양병원 간호사를 대상으로 한 $\operatorname{Kim} \& \operatorname{Kim}[6]$ 은 3.42점으로 본 연구보다 높게 조사되어 본 연구 결과와 차 이가 있어 반복 연구가 필요할 것으로 생각된다. 대부분의 요양병원 간호사의 직무 스트 레스는 중등도 이상의 직무 스트레스를 느끼는 것으로 조사되고 있으나 본 연구에서는 평균 이하로 나타났고, 일반적 특성에 따른 직무 스트레스는 경력과 급여에 따라 유의한 
차이를 보였으며, 경력이 낮을수록, 급여가 낮을수록 직무 스트레스가 높게 나타났다. 즉 임상 경력이 많을수록 직무에 대한 경험과 노련함으로 자신의 직무에 대한 성취감이 높아 직무 스트레스가 낮고, 임상 경력이 적은 간호사는 요양병원의 특성 상 만성질환자 와 고령의 대상자를 간호하는데 과중한 업무 부담감과 책임감 등으로 직무 스트레스가 높은 것으로 생각된다. 특히, 과다한 업무에 낮은 임금체계는 직무 스트레스를 증가시키 는 요인으로 사료되어 요양병원 간호사의 임금 체계에 대한 개선이 필요할 것으로 생각 된다.

대상자의 이직 의도는 5점 만점에 평균 3.36점으로 나타났다. 요양병원 간호사를 대상 으로 한 Kang, Kwon \& Kim[26]은 3.14점으로 본 연구 결과와 유사하였다. 일반적 특성에 따른 이직 의도는 학력, 근무형태, 건강상태에 따라서 유의한 차이를 보였으며, 사후 분 석 결과 학력이 낮을수록, 3교대 근무, 건강하지 않다고 답변한 사람이 이직 의도가 높 은 것으로 조사되었다. 요양병원 간호사를 대상으로 한 Park[27]의 연구에서도 연령, 직 위, 근무형태, 급여수준 등에 따라서 이직 의도가 높게 나와서 본 연구 결과와 부분 일 치하였다. 즉, 교대 근무인 간호사는 3 교대 근무의 부담감과 특히 밤근무에 대한 업무와 스트레스가 높을 것으로 사료되며, 건강 상태가 안 좋을수록 이직 의도가 높아서 요양병 원 간호사의 이직 의도를 낮출 수 있는 중재 프로그램이 개발과 학력 간의 차이에 대한 연구가 필요할 것으로 생각된다.

요양병원 간호사를 대상으로 한 의사소통 능력, 직무만족도, 직무 스트레스 및 이직 의도간의 상관관계를 살펴본 결과 의사소통 능력과 이직 의도 $(\mathrm{r}=-.179, \mathrm{p}<.01)$, 직무만 족도와 이직 의도 $(\mathrm{r}=-.512, \mathrm{p}<.001)$ 는 부적 상관관계를 보였다. 하지만 직무 스트레스와 이직 의도는 상관관계가 없었다. 요양병원 간호사를 대상으로 한 Kim \& Kim[6]의 연구 에서도 직무 스트레스와 이직 의도와의 유의한 관련이 없는 것으로 나타났지만 Kang, Kwon \& Kim[26]의 연구에서는 정적 상관관계가 있는 것으로 나타나 반복 연구가 필요할 것으로 생각된다. 본 연구에서 직무 스트레스가 이직 의도에 유의한 관련이 없는 것으로 나타난 이유는 임상 경력을 1년 10년 등으로 10년씩 나눠서 조사하여 직무 스트레스가 낮게 나온 것으로 생각된다. 직무 스트레스는 임상 경력이 많은 간호사보다는 임상 경력 이 낮고 경험이 부족한 신규 간호사에게 많이 나타날 것으로 생각되어 반복 연구에서는 요양병원 간호사들의 임상경력을 좀더 세분화하고, 다른 병동 간호사들과 어떤 차이가 있는지에 대한 것을 확인할 필요가 있다. 요양병원 간호사의 이직 의도와 직무 만족도는 부적 상관관계를 보였고 Moon[28]의 연구에서도 이직 의도에 가장 큰 영향을 미치는 변 수가 직무만족도로 조사되어 본 연구 결과를 지지하였다. 이에 요양병원 간호사의 직무 만족도를 높일 수 있는 프로그램 개발이 필요할 것으로 생각된다.

마지막으로 요양병원 간호사의 이직 의도에 영향을 미치는 요인으로 의사소통 능력이 영향을 미치는 요인이었다. Kang, Kwon \& Kim[26]의 연구에서는 의사소통 능력이 이직의 도에 영향을 미치지 않는 결과를 보여 본 연구 결과와 상반된 결과를 보였고, 요양병원 간호사를 대상으로 이직 의도와 의사소통 능력과의 관계에 관한 연구가 미비하여 비교가 어려우므로 반복 연구를 통해 다양한 조절변수를 조사하여 비교가 필요할 것으로 생각된 다.

\section{5. 결론 및 제언}

본 연구는 요양병원 간호사를 대상으로 의사소통 능력, 직무만족도, 직무 스트레스와 
이직 의도에 대해서 알아보고 이직 의도에 영향을 미치는 요인을 파악하기 위해 수행되 었다. 연구 결과는 다음과 같다. 이직의도는 의사소통 능력과 직무만족도에 따라 유의한 차이가 있었고 직무 스트레스와 이직 의도 간에의 유의한 상관관계가 없었다. 본 연구 결과에서 요양병원 간호사의 이직 의도에 영향을 미치는 요인으로는 의사소통 능력으로 나타났다. 이상의 연구 결과를 바탕으로 다음과 같이 제언하고자 한다. 본 연구에서는 $\mathrm{S}$ 시와 Y시에 소재한 18 곳의 요양병원의 간호사를 대상으로 한정하였기에 일반화하는데 제 한점이 있다.

첫째, 요양병원 간호사의 이직 의도와 의사소통 능력의 연관성을 확인할 수 있는 반복 연구가 필요하다. 둘째, 본 연구 대상자는 일부 지역에 소재한 요양병원을 대상으로 실 시하여 반복 연구를 통해 일반화 할 수 있는 다양한 지역과 충분한 대상자를 선정이 필 요하다.

\section{6. 감사의 글}

이 연구는 2021 년도 광주대학교 대학 연구비의 지원을 받아 수행되었음.

\section{References}

[1] Long-term care elderly cohort establishment study, National Health Insurance Corporation, (2017)

[2 Percentage of elderly people aged 65and over, Korean Statistical Information Service, (2018)

[3] U. H. Kim, S. Y. Moon, The Effect of Health Status on Sleep Quality and Quality of Life among Elderly patient in geriatric hospitals, Journal of Digital Convergence, (2014), Vol.12, No.11, pp.415-426, DOI: 10.14400/JDC.2014.12.11.415

[4] Status of medical institutions, Statistics Korea, (2018)

[5] H. Y. Jung, G. I. Jung, Influential Factors on Turnover Intention of Nurses in Long-term Care Hospitals, The Korean Journal of Health Service Management, (2015), Vol.9, No.3, pp.95-106, UCI: G704-SER000002085.2015.9.3.008

[6] J. R. Kim, K. H. Kim, A Study on Job Stress and the Turnover Intention of Long-Term Care Hospital Nurses, Health \& Nursing, (2010), Vol.22, No.2, pp.1-11.

[7] E. J. Kim, M. O. Koo, Recognition for nursing competency importance, nursing competency level, and their influencing factors of nurses in the long-term care hospitals, Journal of Korea Academia-Industrial cooperation Society, (2015), Vol.16, No.3, pp.1989-2001, DOI: 10.5762/KAIS.2015.16.3.1989

[8] S. J. Jeong, K. H. Kim, Empathy ability communication ability and nursing performance of registered nurses and nursing assistants in long-term care hospitals, Journal of Korean Academy of Nursing Administration, (2017), Vol.23, No.3, pp.249-258, DOI: 10.11111/jkana.2017.23.3.249

[9] S. H. Lee, Multi level analysis of factors related to quality service in long term care hopitals, Journal of Korean Academy of Nursing, (2009), Vol.39, No.3, pp.409-421, DOI: 10.4040/jkan.2009.39.3.409

[10] E. J. Jo, Relationship between prefessional self-concept and burnout of nurses in geriatric hospital, Gosin University, Master's thesis, (2007)

[11] H. S. Lee, J. K. Kim, Relationship among communication Competence, Communication types and organizational commitment in Hospital Nurses, Journal of Korean Academy of Nursing Administration, (2010), Vol.16, No.4, pp.488496, UCI: G704-001792.2010.16.4.007

[12] Y. H. Lee, A study on job stress and job satisfaction of nurses in long-term care hospital, Hanyang University, Master's thesis, (2010) 
[13] S. J. Kang, I. S. Kim, A Comparative Study on the Job Stress and Satisfacion of the Oriental and Western Common University Hospital Nurses, The Medical Journal of Chosun University, (2006), Vol.31, No.3, pp.90-101.

[14] Y. O. Park, K. J. Lee, Y. H. Jo, H. J. Park, Factors Affecting Turnover Intention of Nurses in Long-term Care Facilities for Elderly People, Journal of Korean Gerontological Nursing, (2009), Vol.11, No.1, pp.81-89, UCI: G704SER000008641.2009.11.1.004

[15] G. H. Hur, Construction and validation of a global interpersonal communication competence sacle, Korean Journal of Journalism \& Communication Studies, (2003), Vol.47, No.6, pp.380-408, UCI: G704-000203.2003.47.6.003

[16] H. S. Lee, J. K. Kim, Relationship among communication competence, communication types and organizational commitment in hospital nurses, Journal of Korean Academy of Nursing Administration, (2010), Vol.16, No.4, pp.488496, UCI: G704-001792.2010.16.4.007

[17] D. B. Slavitt, P. L. Stamps, E. B. Piedmont, A. M. B. Haase, Nurses' satisfaction with their work situation, Nursing Research, (1978), Vol.27, No.2, pp.114-120, DOI: 10.1097/00006199-197803000-00018

[18] M. J. Kim, M. O. Gu, The development of the stress measurement tool for staff nurses working in the hospital, Journal of Korean Academy of Nursing, (1984), Vol.14, No.2, pp.28-37.

[19] W. H. Mobley, Employee turnover : Causes, Consequences, and Control, Addison-Wesley, (1982)

[20] M. R. Kim, Influential Factors on Turnover Intention of Nurses: The Affect of Nurse's Organizational Commitment and Career Commitment to Turnover Intention, Journal of Korean Academy of Nursing Administration, (2007), Vol.13, No.3, pp.335-344, UCI: G704-001792.2007.13.3.003

[21] E. H. Jung, The Effect of Positive Psychological Capital on the Communication Competence and Job Satisfaction of Geriatric Hospital Nurses, Journal of the Korea Entertainment Industry Assoiciation, (2019), Vol.13, No.1, pp.235-243, DOI: $10.21184 /$ jkeia.2019.1.13.1.235

[22] S. M. Han, S. J. Park, The Effects of Communication Skill and Job Stress on Organizational Effectiveness of Geriatric Hospital Nurses, Nursing and Health Issues, (2019), Vol.24, No.2, pp.124-132.

[23] M. W. Lee, S. G. Lee, Y. S. Choy, The Influence of Job Satisfaction on Turnover Intention of Nurses in Geriatric Hospital, Korea Journal of Hospital Management, (2016), Vol.21, No.3, pp.22-36, UCI: G704-001432.2016.21.3.004

[24] J. S. Lee, The relationship on nurses' self-leadership, job satisfaction and nursing performance, Hanyang University, Master's thesis, (2010)

[25] H. J. Yi, University hospital nurse's job stress, job satisfaction and employee turnover study : Comparative analysis of cancer wards and general wards, The Catholic University, Master's thesis, (2014)

[26] Y. S. Kang, Y. C. Kwon, Y. A. Kim, The Effect of Communication Competency and Job Stress of Long Term Care Hospital Nurses on Turnover Intention :focused on control effect of emotional intelligence, Journal of Digital Convergence, (2018), Vol.16, No.12, pp.449-457, DOI: 10.14400/JDC.2018.16.12.449

[27] H. J. Park, Relationship between delegation level of nursing activities, nursing professionalism and turnover intention in long-term care hopsital nurses, Wonkwang University, Master's thesis, (2016)

[28] S. J. Moon, Recognition of Geriatric Hospital Nurse for Medical Institution Certification, Job Satisfaction and Job Stress, Study on the Turnover Intention, Journal of the Korean Society for Multicultural Health, (2015), Vol.5, No.2, pp.55-64. 